\title{
武夷山49种木本植物叶片与细根经济谱
}

\author{
王钊渘 ${ }^{1}$ 陈晓萍 ${ }^{1}$ 程 英 $^{2}$ 王满堂 $^{3}$ 钟全林 $^{1,4}$ 李 曼 ${ }^{1}$ 程栋梁 ${ }^{1,4^{*}}$ \\ ${ }^{1}$ 福建师范大学福建省植物生理生态重点实验室, 福州 350007; ${ }^{2}$ 江西武夷山国家级自然保护区管理局, 江西上饶 334500; ${ }^{3}$ 寿庄学院城市与建筑工程 \\ 学院, 山东菄庄 $277160 ;{ }^{4}$ 福建师范大学地理研究所, 福州 350007
}

摘 要 植物经济谱能够阐述维管植物在资源获取和储存之间的权衡策略, 为理解生态位分化和物种共存机制等提供科学 依据。该研究通过对武夷山49种木本植物的单叶面积 $(I L A)$ 、比叶面积 $(S L A)$ 、叶碳含量 $(L C C)$ 、叶氮含量 $(L N C)$ 和叶磷含量 $(L P C)$ 等 5 个叶片性状以及根组织密度 $(R T D)$ 、比根长 $(S R L)$ 、比根面积 $(S R A)$ 、根碳含量 $(R C C)$ 、根氮含量 $(R N C)$ 和根磷含量 $(R P C)$ 等 6 个细根性状进行测定, 探讨木本植物叶片与细根经济谱是否存在以及常绿和落叶物种间的植物经济谱差异。结果表明: 沿着 性状贡献率相对较大的PC1轴, 能够定义出叶经济谱(LES)、根经济谱(RES)和整株植物经济谱(WPES)。大部分常绿物种分布 在经济谱保守的一侧, 而大部分落叶物种聚集在获取的一侧。此外, 叶片PC1、细根PC1和整株植物PC1的两两得分之间均存 在显著正相关关系, 常绿和落叶物种具有共同的异速指数, 但不存在共同的异速常数。这些结果揭示了亚热带物种叶片与细 根的策略遵循着WPES的协调整合, 表明叶片、细根以及整株植物之间是采取协同变化的资源策略, 而分布于经济谱两端的 常绿和落叶物种则是通过不同的方式来构建WPES。

关键词 权衡策略; 常绿物种; 落叶物种; 植物功能性状; 植物经济谱; 武夷山

王钊颖, 陈晓萍, 程英, 王满堂, 钟全林, 李曼, 程栋梁 (2021). 武夷山49种木本植物叶片与细根经济谱. 植物生态学报, 45, 242-252. DOI: 10.17521/cjpe.2020.0280

\section{Leaf and fine root economics spectrum across 49 woody plant species in Wuyi Mountains}

WANG Zhao-Ying ${ }^{1}$, CHEN Xiao-Ping ${ }^{1}$, CHENG Ying ${ }^{2}$, WANG Man-Tang ${ }^{3}$, ZHONG Quan-Lin ${ }^{1,4}$, LI Man ${ }^{1}$, and CHENG Dong-Liang ${ }^{1,4^{*}}$

${ }^{1}$ Fujian Provincial Key Laboratory of Plant Eco-physiology, Fujian Normal University, Fuzhou 350007, China; ${ }^{2}$ Administrative Bureau of Jiangxi Wuyishan National Nature Reserve, Shangrao, Jiangxi 334500, China; ${ }^{3}$ School of City and Architecture Engineering, Zaozhuang University, Zaozhuang, Shandong 277160, China; and ${ }^{4}$ Institute of Geography, Fujian Normal University, Fuzhou 350007, China

\section{Abstract}

Aims The plant economics spectrum would explain the trade-off strategies of vascular plants between resource acquisition and resource storage, and provide a scientific basis for understanding the mechanisms of niche differentiation and species coexistence.

Methods In this study, we measured leaf/root traits of 49 woody plants species in Wuyi Mountains, including individual leaf area (ILA), specific leaf area (SLA), leaf carbon content (LCC), leaf nitrogen content (LNC) and leaf phosphorus content $(L P C)$, root tissue density $(R T D)$, specific root length $(S R L)$, specific root surface area $(S R A)$, root carbon content $(R C C)$, root nitrogen content $(R N C)$ and root phosphorus content $(R P C)$. Then, we detected if the leaf and fine root economics spectrum of the plants exist, and analyzed the differences of the plant economics spectrum between evergreen and deciduous species.

Important findings The results showed that along the PC1 axis, a leaf economics spectrum (LES), a root economics spectrum (RES) and a whole-plant economics spectrum (WPES) can be defined, respectively. Most of the evergreen species were on the conservative side, while deciduous species, on the acquisitive side of the economics spectrum. There were significant positive correlations among the scores of leaf PC1, root PC1 and whole-plant PC1. In the relationships, evergreen and deciduous species shared common scaling exponents, but common scaling constants lack, revealing that the leaf and root strategies of the subtropical species are coordinated toward the integration of WPES. The evergreen and deciduous species distributed at different sides of the economics spectrum are

收稿日期Received: 2020-08-14 接受日期Accepted: 2021-01-26

基金项目: 国家自然科学基金(32071555、31722007和31971643)、国家重点研发计划(2017YFC0505400)和福建省杰出青年滚动项目(2018J07003)。 Supported by the National Natural Science Foundation of China (32071555, 31722007 and 31971643), the National Key R\&D Program of China (2017YFC0505400), and the Fujian Natural Science Funds for Distinguished Young Scholars (2018J07003).

* 通信作者Corresponding author (chengdl02@aliyun.com) 
in different ways to construct the WPES.

Key words trade-off strategy; evergreen species; deciduous species; plant functional traits; plant economics spectrum; Wuyi Mountains

Wang ZY, Chen XP, Cheng Y, Wang MT, Zhong QL, Li M, Cheng DL (2021). Leaf and fine root economics spectrum across 49 woody plant species in Wuyi Mountains. Chinese Journal of Plant Ecology, 45, 242-252. DOI: 10.17521/cjpe.2020.0280

“植物功能性状”是指对植物体定植、存活、适 应度等具有潜在显著影响的一系列植物属性(Reich et al., 2003), 是植物在长期进化过程中适应环境的 产物(Díaz et al., 2016), 并且能对生态系统过程产 生强烈影响(Cornelissen et al., 2003)。将经济学的 “投资-收益权衡”理论应用到植物的资源分配研究 中, 可定量分析植物叶片功能性状间的相互关系 (陈芗婷和许振柱, 2014)。Wright等(2004)在全球尺 度上定义出一条连续变化的叶功能性状组合谱, 即 “叶经济谱(LES)”, 用以阐述维管植物资源获取和 储存之间的权衡策略, 其可以通过性状指标的变化 范围及其数量关系表现出来(Wright et al., 2005)。谱 的一端代表植物的“快速投资-收益型”策略，拥有该 特征的物种具有廉价的组织投资与快速的投资回报 (即获取策略); 而另一端则代表植物的“缓慢投资收益型”策略, 拥有该特征的物种具有昂贵的组织 投资和较慢的投资回报(即保守策略)(Wright et al., 2004; Reich, 2014; Zhao et al., 2017)。在后续的研究 中, 经济谱研究陆续被相关生态学者推广到茎 (Baraloto et al., 2010; Méndez-Alonzo et al., 2012), 根(Kong et al., 2016; Roumet et al., 2016), 整株植物 (Freschet et al., 2010; de la Riva et al., 2016), 不同层 次的群落结构(Pérez-Ramos et al., 2012; Funk \& Cornwell, 2013; Li et al., 2019)及生态系统(Freschet et al., 2013; 于鸿荣等, 2014)。叶片作为维持陆地生 态系统机能的一个最基本要素, 不仅是植物光合作 用以及物质生产的主要器官, 而且是植物和大气环 境进行水气交换的主要器官(毛伟等, 2012)。细根(包 括经常定植其中的菌根形成的菌丝)在植物中起着 吸收水分和养分的作用(Chen et al., 2019), 细根的 生产、周转是森林生态系统进行物质循环以及能量 流动的重要组成部分(Eissenstat \& Yanai, 1997)。二 者对植物生长及森林生态系统健康维持具有重要作 用, 因此, 本研究将这两个代谢活性较强的植物器 官作为研究对象。

独立于生境的植物经济谱, 能够定量地解释植
物总体在生长速率及胁迫环境中的耐受策略差异 (曲鹏等, 2018)。有研究表明, 植物存在与LES类似 的代表根在生产力与持久性之间权衡策略的根经济 谱(RES)(Reich, 2014; Prieto et al., 2015), 植物的根 性状沿着两种不同的策略边界范围演化: 一种是具 有保守性策略的粗根系植物, 而另一种是具有获取 性策略的细根系植物(Ma et al., 2018)。Ding等(2020) 的研究指出, 细根性状的变异分为两个主要维度: 第一维度主要由根直径 $(R D)$ 和比根长 $(S R L)$ 代表, 表示根寿命和资源获取效率之间的权衡; 第二维度 代表了根养分(即N、P) 和根组织密度 $(R T D)$ 的协调变 化, 表示资源吸收的获取-保守权衡, 即RES。但 Kong等(2019)研究发现, 木本植物的 $R D$ 与 $R T D$ 、根 氮含量 $(R N C)$ 之间存在非线性关系, 这种非线性关 系不支持RES的预测。因此木本植物RES 是否存在 仍值得研究。除此之外, 由于生物普遍存在强烈的 物理限制以及性状和生活史的权衡选择(Reich et al., 1999), Reich (2014)认为所有器官中存在统一的资 源获取和处理速率(快、中或慢速), 存在一条综合的 整株植物经济谱(WPES)。关于叶和根之间的关系, Freschet等(2010)、de la Riva等(2016)、Wang等(2017) 和Liu等(2010)诸多学者的研究均支持二者及其与 整株植物之间的功能性状存在高度协调的观点。然 而, Fortunel等(2012)研究发现木质根性状与叶性状 并无显著相关; Isaac等(2017)还发现种内LES和RES 彼此独立, 根性状会随环境条件而变化, 但叶性状 及其功能不一定会发生相应的变化。有研究表明, 当设置不同的处理和环境梯度时, 叶、根性状间的 相关性并不一致(Reich et al., 1998; Craine \& Lee, 2003; Craine et al., 2005; Tjoelker et al., 2005; Withington et al., 2006; Liu et al., 2010)。因此, 关于植物 不同器官(即叶和根)的性状如何在不同物种之间共 变, 以及这种共变与整株植物经济谱的相关程度等 均存在争议(Freschet et al., 2010; de la Riva et al., 2016), 表明这仍然是一个值得研究的问题。通常, 良好的叶功能取决于根部吸收的水分和养分, 而根 部生长又取决于叶光合作用产生的碳水化合物 
(Chapin III, 1980)。植物叶和根的生态策略应该是建 立在WPES上的, 叶和根性状的变异共同决定了物 种的表现(Grime et al., 1997; Pérez-Ramos et al., 2012; Poorter et al., 2014; Reich, 2014)。因此, 本研 究假设武夷山木本植物中存在LES和RES, 它们二 者与WPES紧密结合且相互之间高度协调(假设1)。

植物经济谱能够反映具有相似策略的物种如何 沿着性状变异轴汇集或分散(Díaz et al., 2016; Zhao et al., 2017)。Wright等(2004)指出当物种按照叶习性 来划分时, 不同物种的叶片投资策略会沿着全球叶 经济谱分布, 即在LES上能够区分出常绿和落叶物 种。常绿和落叶物种在叶经济性状方面的确存在一 定的差异。与常绿物种相比, 落叶物种的叶面积较 大(唐青青等, 2016), 单位面积的叶质量较低(即 LMA 低), 叶片养分的含量相对较高, 光合速率也较 高(Reich et al., 1997; Aerts, 1999; Westoby et al., 2002; Wright et al., 2004)。除此之外, 在叶和根形态 性状关系上, 落叶进化枝在比叶面积 $(S L A)$ 和比根 长 $(S R L)$ 间表现出显著的负相关关系(高SLA可以在 短生长季节促进更快生长, 而低 $S R L$ 可以保护根免 于冻结(Geng et al., 2014)); 但常绿进化枝显示出较 弱的正相关关系或无显著相关性(Medeiros et al., 2017)。落叶物种由于相对频繁地落叶和生长新叶, 对土壤养分的需求量大, 有高的资源获取率, 属于 营养获取型; 常绿物种叶片寿命长, 对养分需求较 少, 故常绿习性被认为是对贫痊土壤生境的一种适 应性(Aerts, 1995; Givnish, 2002)。上述研究结果表 明, 落叶物种倾向于采取获取策略, 而常绿种类通 常采取保守策略(Givnish, 2002)。但研究叶性状关系 并不能简单地直接套用其他尺度的研究结果, 全球 尺度的LES 是否适用于局地尺度仍值得探究(何芸 雨等, 2019)。本研究力求验证武夷山的常绿和落叶 物种是否也能够沿着综合的WPES被区分开来。因 此, 本研究假设武夷山的常绿和落叶物种将分布于
植物经济谱的两侧: 常绿物种分布在保守的一侧, 落叶物种分布在获取的一侧(假设2)。

本研究试图通过分析武夷山 49 个物种的 5 个叶 片性状和 6 个细根性状来验证上述两个假设, 解决 两个科学问题, 即(1)武夷山叶片与细根的生存策略 是否遵循WPES的综合协调; (2)常绿和落叶物种在 植物经济谱范围内如何分布。

\section{1 材料和方法}

\section{1 研究区概况}

本研究是在位于中国东南部的江西武夷山国家 级自然保护区 $\left(27.80^{\circ}-28.01^{\circ} \mathrm{N}, 117.66^{\circ}-117.93^{\circ} \mathrm{E}\right)$ 进行的。该区平均海拔1 $200 \mathrm{~m}$ 左右, 属于中亚热带 季风气候, 年平均气温为13.2-14.8 ${ }^{\circ} \mathrm{C}$, 随海拔升高 而降低; 年降水量为2 $583 \mathrm{~mm}$, 降水集中于4-6月; 年蒸发量为778 mm, 年日照时间为774-1 $144 \mathrm{~h}$, 年 平均相对湿度为 $72 \%-92 \%$, 平均年无霜期为 231 天 (刘信中和方福生, 2001)。土壤具有典型的亚热带中 山土壤的特点, 海拔从低到高可分为山地黄红壤 (400-600 m)、山地黄壤(600-1 300 m)、山地暗黄棕 壤(1 300-1900 m)和山地草甸土(1 $900 \mathrm{~m}$ 以上); 境 内森林覆盖率达到 $95 \%$ 以上, 生物多样性十分丰富 (郑成洋等, 2004)。

\section{2 样地设置}

本研究开展于2016年7月, 依据武夷山常绿阔 叶林(海拔1 $319 \mathrm{~m}$ )、针阔混交林(海拔1 $697 \mathrm{~m}$ )和落 叶林(海拔1 $818 \mathrm{~m}$ )群落植物的实际分布情况, 采用 样地调查法, 在这 3 个森林群落中分别设置 1 个大样 地。每个样地内再设 3 个 $20 \mathrm{~m} \times 20 \mathrm{~m}$ 的样方, 每个样 方距离林分边缘至少 $20 \mathrm{~m}$ 。再将每个样方划分为 4 个 $10 \mathrm{~m} \times 10 \mathrm{~m}$ 的小样方, 并对样方内所有胸径 $\geqslant 5$ $\mathrm{cm}$ 的林木进行每木检尺，记录物种名、胸径、树高 并计算林分密度(表1)。

样地内的优势种有木荷(Schima superba), 马银

表1 武夷山不同群落的样地概况(平均值土标准误)

Table 1 Site status of different forest communities in the Wuyi Mountains (mean $\pm S E$ )

\begin{tabular}{|c|c|c|c|c|c|c|}
\hline $\begin{array}{l}\text { 群落 } \\
\text { Community }\end{array}$ & $\begin{array}{c}\text { 林分密度 } \\
\text { Stand density } \\
\left(\text { trees } \cdot \mathrm{hm}^{-2} \text { ) }\right.\end{array}$ & $\begin{array}{c}\text { 平均胸径 } \\
\text { Mean } D B H \\
\text { (cm) }\end{array}$ & $\begin{array}{c}\text { 平均树高 } \\
\text { Mean height } \\
\text { (m) }\end{array}$ & $\begin{array}{c}\text { 土壤总碳含量 } \\
\text { Soil total C content } \\
\left(\mathrm{mg} \cdot \mathrm{g}^{-1}\right)\end{array}$ & $\begin{array}{c}\text { 土壤总氮含量 } \\
\text { Soil total } \mathrm{N} \text { content } \\
\left(\mathrm{mg} \cdot \mathrm{g}^{-1}\right)\end{array}$ & $\begin{array}{c}\text { 土壤总磷含量 } \\
\text { Soil total P content } \\
\left(\mathrm{mg} \cdot \mathrm{g}^{-1}\right)\end{array}$ \\
\hline EF & $3033.33 \pm 200.00^{\mathrm{a}}$ & $13.77 \pm 1.46^{\mathrm{b}}$ & $7.87 \pm 0.07^{\mathrm{b}}$ & $68.88 \pm 0.59^{\mathrm{a}}$ & $4.84 \pm 0.04^{\mathrm{a}}$ & $0.46 \pm 0.01^{\mathrm{b}}$ \\
\hline MF & $1133.33 \pm 164.15^{\mathrm{b}}$ & $21.39 \pm 0.80^{\mathrm{a}}$ & $10.56 \pm 0.21^{\mathrm{a}}$ & $78.71 \pm 4.36^{\mathrm{a}}$ & $5.25 \pm 0.27^{\mathrm{a}}$ & $0.38 \pm 0.02^{\mathrm{c}}$ \\
\hline DF & $2725.00 \pm 163.94^{\mathrm{a}}$ & $11.47 \pm 0.67^{\mathrm{b}}$ & $6.94 \pm 0.24^{\mathrm{b}}$ & $75.16 \pm 5.23^{\mathrm{a}}$ & $6.05 \pm 0.22^{\mathrm{a}}$ & $0.65 \pm 0.01^{\mathrm{a}}$ \\
\hline
\end{tabular}

$\mathrm{DF}$, 落叶林; EF, 常绿阔叶林; MF, 针阔混交林。同列不同小写字母表示群落间差异显著 $(p<0.05)$ 。

DF, deciduous forest; EF, evergreen forest; MF, coniferous and broad-leaved mixed forest. $D B H$, diameter at breast height. Different small letters in the same column indicate significant differences among communities $(p<0.05)$.

www.plant-ecology.com 
花(Rhododendron ovatum), 猴头杜鹃(Rhododendron simiarum), 铁杉 (Tsuga chinensis), 大屿八角 (Illicium angustisepalum), 白檀(Symplocos paniculata)等。所选择的植物隶属于 24 科 36 属, 共 49 种木 本植物。其中, 有 3 个物种在 3 个群落中均有, 有 5 个 物种在两个群落中均有, 同样的物种在不同的森林 群落中当作不同物种进行分析。根据叶习性, 群落 中的木本植物被划分为常绿和落叶两大类(附录I)。

\section{3 样品采集}

对每个物种选取3株标准木进行采样。所有样品 采集后均低温保存, 直到它们被运送到实验室进行 下一步分析。首先, 在每株标准木上随机选择树冠 外层的3个无病虫害的当年生末端活枝。取样后, 将 每个枝条用湿纸巾覆盖并储存在密封袋中, 回到驻 地后从每个枝条上采集中等大小的成熟叶片, 要求 叶片完全展开且没有明显的叶面积损失。其次, 细 根取样是在距树干中心 $0.5 \mathrm{~m}$ 左右的冠幅内沿 3 个方 位 (以树干为原点的圆的三等分线处)进行。由于森 林树木根系错综复杂, 为保证根系取样准确, 我们 采取的方法是先用铲子将地面的凋落物清理干净, 找出每株标准木的主根, 再沿主根延伸方向从土壤 层顶部收集细根(直径 $\leqslant 2 \mathrm{~mm}$ ), 最后分别装入密封 袋中。待回到驻地后, 将细根装入网袋中在流水下 淘洗, 以除去土壤颗粒和有机碎屑, 再根据其形态 (弹性和颜色等)分选出活细根。

在每个大样地内, 随机选择 3 个受干扰较小的 土壤剖面, 按0-10 cm及10-20 cm土层采集土壤样 品, 去除落叶和根系后, 将样品充分混合以测定化 学指标。

\section{4 指标测定}

本研究选择 11 个植物功能性状进行测量, 包括 单叶面积 $(I L A)$ 、比叶面积 $(S L A)$ 、叶碳含量 $(L C C)$ 、 叶氮含量 $(L N C)$ 和叶磷含量 $(L P C)$ 等 5 个叶片性状, 以及根组织密度 $(R T D)$ 、比根长 $(S R L)$ 、比根面积 $(S R A)$ 、根碳含量 $(R C C)$ 、根氮含量 $(R N C)$ 和根磷含 量 $(R P C)$ 等 6 个细根性状, 计算这些植物性状的平均 值、最大值、最小值和变异系数(表2)。

到达实验室后, 待每个枝条上的成熟叶片收集 完毕, 记录叶片数量, 然后使用扫描仪(Epson Perfection V37, Epson (China), Beijing, China)扫描叶片 图像后使用Photoshop软件计算叶面积, 以确定ILA。 在活细根挑选完毕后, 同样进行细根图像的扫描,
表2 武夷山49种木本植物叶片和细根测量的性状

Table 2 Plant leaf and fine root traits measured from sampled 49 woody species in the Wuyi Mountains

\begin{tabular}{|c|c|c|c|c|c|}
\hline $\begin{array}{l}\text { 性状 } \\
\text { Trait }\end{array}$ & $\begin{array}{l}\text { 单位 } \\
\text { Unit }\end{array}$ & $\begin{array}{c}\text { 平均值( }(\text { 标准误) } \\
\text { Mean }( \pm S E)\end{array}$ & $\begin{array}{c}\text { 最大值 } \\
\operatorname{Max}\end{array}$ & $\begin{array}{c}\text { 最小值 } \\
\text { Min }\end{array}$ & $\begin{array}{c}\text { 变异系数 } \\
C V\end{array}$ \\
\hline$I L A$ & $\mathrm{~cm}^{2}$ & $22.98 \pm 1.68$ & 56.03 & 0.24 & 56.79 \\
\hline SLA & $\mathrm{cm}^{2} \cdot \mathrm{g}^{-1}$ & $164.54 \pm 8.45$ & 386.95 & 79.54 & 39.78 \\
\hline$L C C$ & $\mathrm{mg} \cdot \mathrm{g}^{-1}$ & $477.56 \pm 3.32$ & 525.14 & 371.38 & 5.39 \\
\hline$L N C$ & $\mathrm{mg} \cdot \mathrm{g}^{-1}$ & $21.07 \pm 0.88$ & 38.75 & 9.54 & 32.36 \\
\hline$L P C$ & $\mathrm{mg} \cdot \mathrm{g}^{-1}$ & $1.34 \pm 0.05$ & 2.40 & 0.66 & 27.91 \\
\hline$R T D$ & $\mathrm{~g} \cdot \mathrm{cm}^{-3}$ & $0.10 \pm 0.003$ & 0.18 & 0.05 & 24.23 \\
\hline$S R L$ & $\mathrm{~cm} \cdot \mathrm{g}^{-1}$ & $1809.01 \pm 56.49$ & 3284.93 & 749.73 & 24.19 \\
\hline$S R A$ & $\mathrm{~cm}^{2} \cdot \mathrm{g}^{-1}$ & $477.00 \pm 11.31$ & 825.78 & 283.10 & 18.37 \\
\hline$R C C$ & $\mathrm{mg} \cdot \mathrm{g}^{-1}$ & $481.55 \pm 3.48$ & 526.99 & 374.11 & 5.60 \\
\hline$R N C$ & $\mathrm{mg} \cdot \mathrm{g}^{-1}$ & $10.19 \pm 0.47$ & 27.14 & 5.88 & 35.56 \\
\hline$R P C$ & $\mathrm{mg} \cdot \mathrm{g}^{-1}$ & $0.60 \pm 0.02$ & 1.34 & 0.27 & 32.31 \\
\hline
\end{tabular}

$I L A$, 单叶面积; $L C C$, 叶碳含量; $L N C$, 叶氮含量; $L P C$, 叶磷含量; $R C C$, 根碳含量; RNC, 根氮含量; RPC, 根磷含量; RTD, 根组织密度; SLA, 比 叶面积; $S R A$, 比根面积; $S R L$, 比根长。

$I L A$, individual leaf area; $L C C$, leaf carbon content; $L N C$, leaf nitrogen content; $L P C$, leaf phosphor content; $R C C$, root carbon content; $R N C$, root nitrogen content; $R P C$, root phosphor content; $R T D$, root tissue density; SLA, specific leaf area; $S R A$, specific root surface area; $S R L$, specific root length.

并使用数字图像分析软件(WinRHIZO Pro 2009b)分 析细根根长 $(\mathrm{cm})$ 、表面积 $\left(\mathrm{cm}^{2}\right)$ 和体积 $\left(\mathrm{cm}^{3}\right)$ 。然后, 将叶片和细根样品在温度为 $75{ }^{\circ} \mathrm{C}$ 的烘箱中烘干 $48 \mathrm{~h}$ 至恒质量, 并用电子天平称量干质量(精确到 $0.01 \mathrm{~g})$, 用以计算 $S L A 、 R T D 、 S R L$ 和 $S R A$ 。最后，用 粉碎机将样品研磨成粉末过篮 $(<0.25 \mathrm{~mm})$, 用以测 定植物和土壤的总 $\mathrm{C} 、$ 总 $\mathrm{N}$ 和总 $\mathrm{P}$ 含量。使用碳氮元 素分析仪(Vario EL III, Elementar, Hanau, Germany) 测定植物总 $\mathrm{C}$ 和总 $\mathrm{N}$ 含量 $(L C C 、 L N C 、 R C C$ 和 $R N C)$, 而土壤总 $\mathrm{C}$ 和总 $\mathrm{N}$ 含量使用碳氮元素分析仪(Vario MAX, Elementar, Hanau, Germany)测定。在 $\mathrm{H}_{2} \mathrm{SO}_{4}$ $\mathrm{H}_{2} \mathrm{O}_{2}$ 中消煮后, 使用连续流动分析仪(San++, Skalar, Breda, Netherlands)测定植物 $\mathrm{P}$ 含量 $(L P C$ 和 $R P C)$ 和土 壤含量。每个森林群落土壤的总 $\mathrm{C} 、$ 总 $\mathrm{N}$ 和总 $\mathrm{P}$ 含量 如表1所示。

\section{5 数据分析}

统计分析中, 每个性状均是使用物种的平均值, 根据需要将性状值进行 $l g$ 转换使其符合或接近正态 分布。首先，使用Pearson相关分析来分析叶片和细 根各性状间的相关性，该情况下不区分常绿和落叶 物种。

其次，使用R语言对LES性状(5个)、RES性状(6 个) 和 WPES 性状(11个), 分别进行主成分分析 (PCA)。PC1和PC2通常能解释较高比例的方差, 这 
些得分在所有后续分析中可用作LES、RES和WPES 的替代。为了理解单个性状和植物资源经济之间的 变异模式, 再次用PC1和PC2得分与每个性状计算 相关性。通过这种方式, 估计每个性状对PC1和PC2 的相对贡献。

为了检验常绿和落叶物种性状之间的差异是否 显著, 使用SPSS 19.0对叶片、细根和整株植物性状 的PC1和PC2得分分别进行独立样本 $t$ 检验。所有统 计检验在 $p<0.05$ 水平被认为是差异显著。

最后, 本研究分析了LES、RES和WPES之间的 关联水平。叶片、细根和整株植物经济谱主要由PC1 轴支配, 双变量的经济谱关系由叶片、细根和整株 植物的PC1得分拟合。通过标准化主轴回归分析 (SMA)方法(Warton et al., 2006), 使用 R语言的 “smatr”程序包(Venables et al., 2019)来确定这3组回 归关系的斜率和截距及其置信区间。为区分常绿和 落叶物种的差异, 对斜率进行异质性检验, 且在斜 率同质时计算共同斜率(Warton \& Weber, 2002), 进 而验证共同截距的存在与否。

\section{2 结果和分析}

\section{1 叶片和细根性状的相关性}

叶片和细根性状间具有显著的相关性(表3)。在 叶片性状中, $S L A$ 与 $L C C$ 呈极显著负相关关系 $(p<$ $0.01)$, 但与 $L N C 、 L P C$ 呈极显著正相关关系 $(p<$ $0.01) ; L N C$ 与 $L P C$ 呈极显著正相关关系 $(p<0.01)$ 。在 细根性状中, $R T D$ 与 $S R A 、 R N C$ 和 $R P C$ 均呈极显著负
相关关系 $(p<0.01) ; S R A$ 与 $S R L 、 R N C$ 和 $R P C$ 均呈极 显著正相关关系 $(p<0.01)$; $R P C$ 与 $R C C$ 呈极显著负 相关关系 $(p<0.01)$, 但与 $R N C$ 呈极显著正相关关系 $(p<0.01)$ 。叶片和细根性状之间也具有显著的相关 性, 如 $I L A$ 和 $S R L$ 呈显著正相关关系 $(p<0.05) ; L C C$ 、 $L N C$ 和 $L P C$ 分别与 $R C C 、 R N C$ 和 $R P C$ 呈显著乃至极 显著正相关关系 $(p<0.05) ; L N C$ 与 $R T D$ 呈显著负相 关关系 $(p<0.05)$, 与 $R P C$ 呈极显著正相关关系 $(p<$ $0.01) ; L P C$ 与 $R N C$ 呈显著正相关关系 $(p<0.05)$ 。

\section{2 叶片、细根和整株植物性状的主成分分析}

根据主成分分析的结果(图1), 能够揭示不同叶 习性物种的资源利用策略。沿着性状贡献率相对较 大的PC1轴(表4), 能够验证常绿和落叶物种是否在 叶经济谱(LES)、根经济谱(RES)和整株植物经济谱 (WPES)上发生分异。

叶片性状的主成分分析结果显示, PC1和PC2分 别占有 $46.7 \%$ 和 $21.5 \%$ 的方差解释率, 合计 $68.2 \%$ 。除 了ILA之外, 其余叶片性状对PC1轴的贡献率都很大 (表4)。PC1轴的一侧是具有大 $L C C$, 小SLA、LNC和 $L P C$ 的物种, 即“缓慢投资-收益”型(保守型)策略物 种; 而另一侧是具有小 $L C C$, 大 $S L A 、 L N C$ 和 $L P C$ 的 物种，即“快速投资-收益”型(获取型)策略物种。PC1 轴相当于LES理论中的“投资-收益”策略轴, 由此能 够定义一条LES。大部分常绿物种分布在LES保守 的一侧, 而大部分落叶物种聚集在获取的一侧(图 $1 \mathrm{~A})$, 常绿物种的PC1轴得分显著高于落叶物种 $(p<$ 0.001 ; 表5)。

表3 叶片和细根性状间的相关系数

Table 3 Correlation coefficients among the measured leaf and fine root traits on log scale

\begin{tabular}{|c|c|c|c|c|c|c|c|c|c|c|}
\hline 性状 Trait & $\lg I L A$ & $\lg S L A$ & $\lg L C C$ & $\lg L N C$ & $\lg L P C$ & $\lg R T D$ & $\lg S R L$ & $\lg S R A$ & $\lg R C C$ & $\lg R N C$ \\
\hline $\lg S L A$ & 0.107 & & & & & & & & & \\
\hline $\lg L C C$ & -0.075 & $-0.367^{* * *}$ & & & & & & & & \\
\hline $\lg L N C$ & 0.140 & $0.708^{* * *}$ & -0.253 & & & & & & & \\
\hline $\lg L P C$ & -0.003 & $0.458^{* *}$ & 0.018 & $0.776^{* *}$ & & & & & & \\
\hline $\lg R T D$ & -0.037 & -0.24 & 0.022 & $-0.295^{*}$ & -0.236 & & & & & \\
\hline $\lg S R L$ & $0.276^{*}$ & 0.014 & -0.077 & 0.003 & -0.116 & -0.200 & & & & \\
\hline $\lg S R A$ & 0.202 & 0.163 & -0.074 & 0.199 & 0.081 & $-0.777^{* * *}$ & $0.768^{* *}$ & & & \\
\hline $\lg R C C$ & -0.049 & -0.114 & $0.596^{* *}$ & -0.094 & 0.036 & 0.078 & -0.119 & -0.163 & & \\
\hline $\lg R N C$ & -0.006 & 0.147 & -0.113 & $0.413^{* *}$ & $0.310^{*}$ & $-0.462^{* *}$ & 0.192 & $0.435^{* *}$ & -0.224 & \\
\hline $\lg R P C$ & -0.081 & 0.194 & -0.207 & $0.362^{* *}$ & $0.310^{*}$ & $-0.572^{* * *}$ & 0.113 & $0.451^{* *}$ & $-0.381^{* *}$ & $0.786^{* *}$ \\
\hline
\end{tabular}

ILA, 单叶面积; $L C C$, 叶碳含量; $L N C$, 叶氮含量; $L P C$, 叶磷含量; RCC, 根碳含量; RNC, 根氮含量; RPC, 根磷含量; RTD, 根组织密度; SLA, 比叶面积; $S R A$, 比根面积; $S R L$, 比根长。* ${ }^{*}, p<0.05 ; * *, p<0.01$ 。

$I L A$, individual leaf area; $L C C$, leaf carbon content; $L N C$, leaf nitrogen content; $L P C$, leaf phosphor content; $R C C$, root carbon content; $R N C$, root nitrogen content; $R P C$, root phosphor content; $R T D$, root tissue density; $S L A$, specific leaf area; $S R A$, specific root surface area; $S R L$, specific root length. *, $p<0.05$; **, $p<0.01$. 

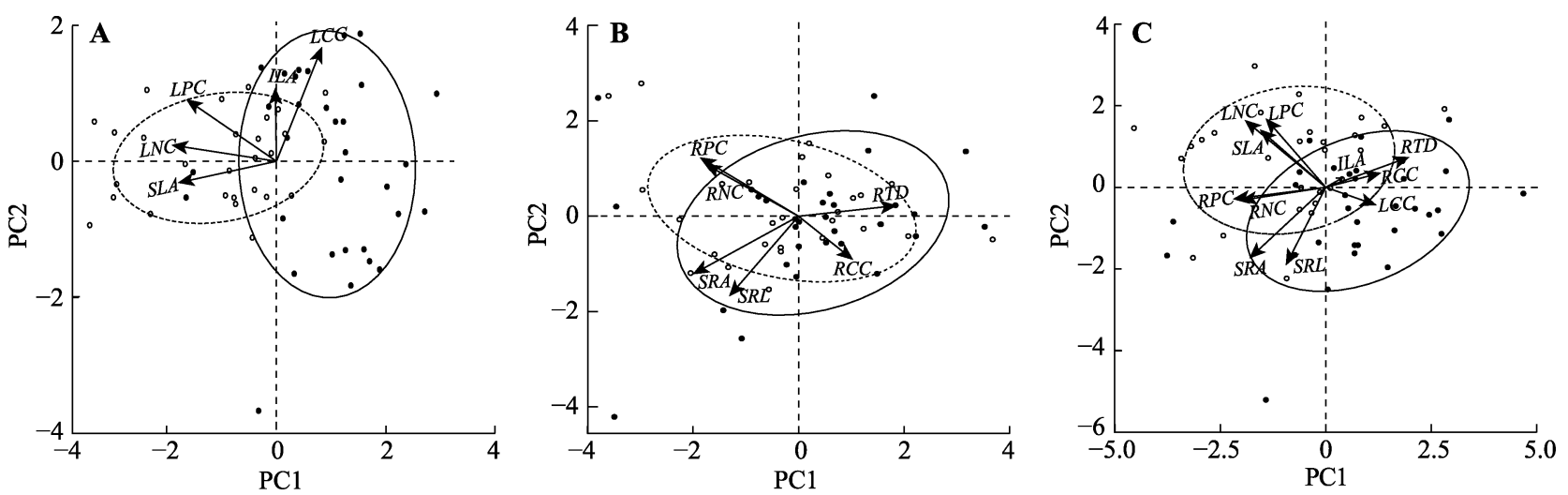

- 常绿 Evergreen 。落叶 Deciduous

图1 叶片、细根和整株植物性状的主成分分析。A, 叶片性状的主成分分析。 B, 细根性状的主成分分析。C, 整株植物性状 的主成分分析。ILA, 单叶面积; $L C C$, 叶碳含量; $L N C$, 叶氮含量; $L P C$, 叶磷含量; RCC, 根碳含量; RNC, 根氮含量; RPC, 根 磷含量; RTD, 根组织密度; SLA, 比叶面积; SRA, 比根面积; SRL, 比根长。

Fig. 1 Principal components analysis (PCA) of the leaf traits, fine root traits and whole-plant traits. A, PCA of leaf traits. B, PCA of fine root traits. C, PCA of whole-plant traits. ILA, individual leaf area; $L C C$, leaf carbon content; $L N C$, leaf nitrogen content; $L P C$, leaf phosphor content; $R C C$, root carbon content; $R N C$, root nitrogen content; $R P C$, root phosphor content; RTD, root tissue density; $S L A$, specific leaf area; $S R A$, specific root surface area; $S R L$, specific root length.

表4 叶片、细根和整株植物经济谱中各个性状与第一和第二主成分得分之间的相关系数

Table 4 Correlation coefficients between individual traits and the scores of the first and second principal components in each of the leaf, fine root and whole-plant economics spectrum

\begin{tabular}{|c|c|c|c|c|c|c|c|}
\hline \multirow{2}{*}{$\begin{array}{l}\text { 性状 } \\
\text { Trait }\end{array}$} & & \multicolumn{2}{|c|}{ 叶片 Leaf } & \multicolumn{2}{|c|}{ 细根 Fine root } & \multicolumn{2}{|c|}{ 整株植物 Whole-plant } \\
\hline & & PC1 & PC2 & PC1 & PC2 & PC1 & PC2 \\
\hline \multirow{5}{*}{$\begin{array}{l}\text { 叶片 } \\
\text { Leaf }\end{array}$} & $\lg I L A$ & -0.094 & $0.283^{*}$ & & & -0.039 & -0.003 \\
\hline & $\lg S L A$ & $-0.843^{* *}$ & -0.159 & & & $-0.550^{* *}$ & $0.535^{* *}$ \\
\hline & $\lg L C C$ & $0.382^{* *}$ & $0.797^{* *}$ & & & $0.385^{* *}$ & -0.124 \\
\hline & $\lg L N C$ & $-0.931^{* *}$ & 0.132 & & & $-0.679^{* *}$ & $0.593^{* *}$ \\
\hline & $\lg L P C$ & $-0.776^{* *}$ & $0.433^{* *}$ & & & $-0.502^{* *}$ & $0.608^{* *}$ \\
\hline \multirow{6}{*}{$\begin{array}{l}\text { 细根 } \\
\text { Fine root }\end{array}$} & $\lg R T D$ & & & $0.775^{* *}$ & 0.100 & $0.698^{* *}$ & $0.284^{*}$ \\
\hline & $\lg S R L$ & & & $-0.545^{* *}$ & $-0.666^{* *}$ & $-0.344^{* *}$ & $-0.641^{* *}$ \\
\hline & $\lg S R A$ & & & $-0.862^{* *}$ & $-0.478^{* *}$ & $-0.684^{* *}$ & $-0.596^{* *}$ \\
\hline & $\lg R C C$ & & & $0.385^{* *}$ & $-0.372^{* *}$ & $0.408^{* *}$ & 0.109 \\
\hline & $\lg R N C$ & & & $-0.760^{* *}$ & $0.419^{* *}$ & $-0.754^{* *}$ & -0.098 \\
\hline & $\lg R P C$ & & & $-0.801^{* *}$ & $0.471^{* *}$ & $-0.791^{* *}$ & -0.111 \\
\hline
\end{tabular}

$I L A$, 单叶面积; $L C C$, 叶碳含量; $L N C$, 叶氮含量; $L P C$, 叶磷含量; $R C C$, 根碳含量; $R N C$, 根氮含量; $R P C$, 根磷含量; $R T D$, 根组织密度; SLA, 比叶面积; $S R A$, 比根面积; $S R L$, 比根长。* ${ }^{*}, p<0.05 ; * *, p<0.01$ 。

$I L A$, individual leaf area; $L C C$, leaf carbon content; $L N C$, leaf nitrogen content; $L P C$, leaf phosphor content; $R C C$, root carbon content; $R N C$, root nitrogen content; $R P C$, root phosphor content; $R T D$, root tissue density; $S L A$, specific leaf area; $S R A$, specific root surface area; $S R L$, specific root length. *, $p<0.05$; **, $p<0.01$.

表5 常绿和落叶物种PC1和PC2得分的差异(平均值土标准误)

Table 5 Differences in PC1 and PC2 scores between evergreen and deciduous species (mean $\pm S E$ )

\begin{tabular}{lcccccc}
\hline 主成分分析 & $\begin{array}{c}\text { 轴 } \\
\text { PCA }\end{array}$ & \multicolumn{2}{c}{$\begin{array}{c}\text { 叶习性 } \\
\text { Leaf habit }\end{array}$} & \multicolumn{2}{c}{$\begin{array}{c}\text { 显著性检验 } \\
\text { Significance test }\end{array}$} \\
\cline { 3 - 4 } & & $\begin{array}{c}\text { 常绿 } \\
\text { Evergreen }\end{array}$ & $\begin{array}{c}\text { 落叶 } \\
\text { Deciduous }\end{array}$ & $t$ & $p$ \\
\hline 叶片 & PC1 & $0.93 \pm 0.19^{\mathrm{a}}$ & $-1.06 \pm 0.24^{\mathrm{b}}$ & 6.569 & 0 \\
Leaf & PC2 & $-0.04 \pm 0.23^{\mathrm{a}}$ & $0.05 \pm 0.12^{\mathrm{a}}$ & -0.364 & 0.717 \\
细根 & PC1 & $0.27 \pm 0.30^{\mathrm{a}}$ & $-0.31 \pm 0.32^{\mathrm{a}}$ & & 1.340 & 0.185 \\
Fine root & PC2 & $-0.14 \pm 0.23^{\mathrm{a}}$ & $0.16 \pm 0.19^{\mathrm{a}}$ & -0.998 & 0.322 \\
整株植物 & PC1 & $0.76 \pm 0.31^{\mathrm{a}}$ & $-0.87 \pm 0.31^{\mathrm{b}}$ & 3.694 & 0 \\
Whole-plant & PC2 & $-0.58 \pm 0.23^{\mathrm{b}}$ & $0.67 \pm 0.23^{\mathrm{a}}$ & -3.833 & 0 \\
\hline
\end{tabular}

同行不同小写字母表示物种间差异显著 $(p<0.05)$ 。

Different small letters in the same row indicate significant differences among species $(p<0.05)$.
细根性状的主成分分析结果显示, PC1和PC2分 别占有 $48.7 \%$ 和 $22.7 \%$ 的方差解释率，合计 $71.4 \%$ 。所 有细根性状对PC1轴的贡献率都很大，且大于PC2 (表4)。PC1轴的一侧是具有大 $R C C$ 和 $R T D$, 小 $S R L$ 、 $S R A 、 R N C$ 和 $R P C$ 的物种，即“缓慢投资-收益”型(保 守型)策略物种; 而另一侧是具有小 $R C C$ 和 $R T D$, 大 $S R L 、 S R A 、 R N C$ 和 $R P C$ 的物种，即“快速投资-收益” 型(获取型)策略物种。PC1轴相当于RES理论中的 “投资-收益”策略轴，由此也能够定义一条RES。常 绿和落叶物种在RES代表获取和保守的两侧均有分 布(图1B), 在PC1轴上不同物种得分的差异不显著 
$(p>0.05$; 表5)。

整株植物性状的主成分分析结果显示, PC1和 PC2 分别占有 $32.2 \%$ 和 $17.7 \%$ 的方差解释率, 合计 $49.9 \%$ 。除了ILA外, 所有性状对PC1轴的贡献率都 很大(表4)。PC1轴的一侧是具有大 $L C C 、 R C C$ 和 $R T D$, 小 $S L A 、 L N C 、 L P C 、 S R L 、 S R A 、 R N C$ 和 $R P C$ 的物 种，即“缓慢投资-收益”型(保守型)策略物种; 而另 一侧是具有小 $L C C 、 R C C$ 和 $R T D$, 大SLA、LNC、LPC、 $S R L 、 S R A 、 R N C$ 和 $R P C$ 的物种，即“快速投资-收益” 型(获取型)策略物种。PC1轴相当于WPES理论中的 “投资-收益”策略轴，由此定义出一条WPES。大部 分常绿物种分布在WPES保守的一侧, 而大部分落 叶物种聚集在获取的一侧(图1C), 常绿物种在PC1 轴上的得分也显著高于落叶物种 $(p<0.001$; 表5)。

\section{3 植物经济谱间的关系}

当不区分常绿和落叶物种时, 叶片PC1与细根 PC1、叶片PC1与整株植物PC1以及细根PC1与整株 植物PC1之间均呈显著正相关关系 $(p<0.05$; 图2)。 当区分常绿和落叶物种时, 除落叶物种在叶片 PC1 与细根PC1关系上无显著相关性之外, 常绿和落叶 物种在上述三组关系中均呈现显著正相关关系。从 决定系数来看, 常绿物种的相关性均优于落叶物 种。除叶片PC1与细根PC1外, 常绿和落叶物种在其 余两组关系中均存在共同斜率 $(p>0.05)$, 但不存在 共同截距 $(p<0.01)$ 。在叶片PC1与整株植物PC1关系 中, 常绿物种的截距显著大于落叶物种; 而细根 PC1与整株植物PC1关系中, 落叶物种的截距则显 著大于常绿物种。

\section{3 讨论}

植物叶片和细根性状之间的内在联系以及叶片 和细根PCA轴的多性状变异共同确定了植物资源分 配的权衡策略，这证实了植物的经济策略不仅仅存 在于单一器官的性状中, 而是作用于整株植物 (Grime et al., 1997), 表明武夷山49种木本植物中存 在着LES、RES和WPES。

\section{1 植物叶片性状与细根性状的耦合}

叶片和细根性状之间及其性状轴之间的显著相 关性表明了LES和RES之间的耦合(Reich，2014; Zhao et al., 2017), 因此本研究证实了假设1, 即经 济谱存在于整株植物水平上。虽然有研究表明叶和 根的性状之间存在解耦演化(Fortunel et al., 2012; Isaac et al., 2017), 但叶和根之间性状协调的观点依 然得到众多研究的支持(Freschet et al., 2010; Liu et al., 2010; de la Riva et al., 2016; Wang et al., 2017)。 有研究表明, 叶、根二者的形态性状(如 $S L A$ 和 $S R L$ ) 存在显著相关性(Liu et al., 2010; Geng et al., 2014; de la Riva et al., 2016; Medeiros et al., 2017)。本研究 中，ILA和 $S R L$ 呈显著正相关关系，表明物种是通过 利用较大的叶进行光合作用固碳, 同时增加比根长 以充分吸收植物生长所需的营养物质(即高 $I L A$ 和 $S R L)$ 。除此之外, 叶和根的 $\mathrm{N}$ 含量(Craine et al., 2005; Liu et al., 2010)、C含量、C:N、木质素含量、干物 质含量、pH (Freschet et al., 2010)、呼吸速率(Tjoelker et al., 2005)等性状指标之间均被证实存在显著相关 性。本研究从群落总体水平上看 $L C C 、 L N C$ 和 $L P C$ 分别与 $R C C 、 R N C$ 和 $R P C$ 呈极显著正相关关系;

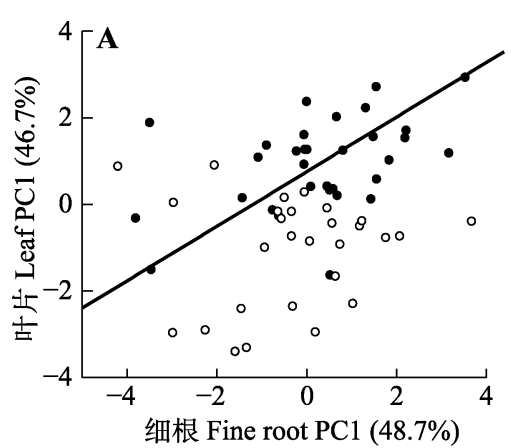

- 常绿 Evergreen

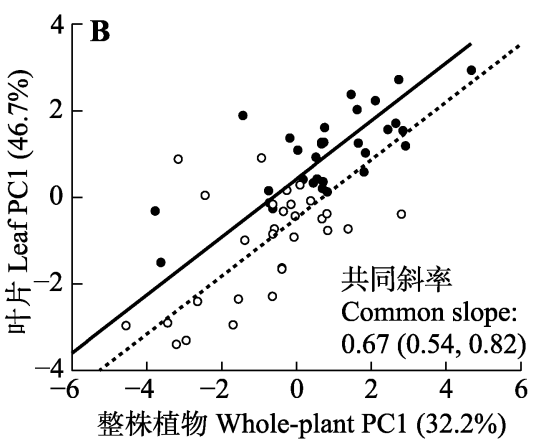

。落叶 Deciduous — 常绿 Evergreen

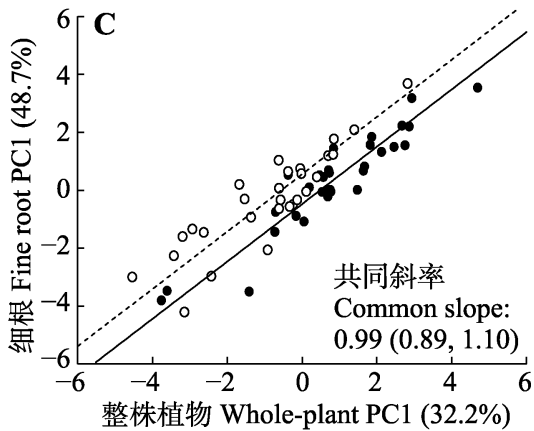

落叶 Deciduous

图2 叶片PC1、细根PC1和整株植物PC1之间的回归关系。A, 叶片PC1和细根PC1之间的关系。 $\mathbf{B}$, 叶片PC1和整株植物PC1 之间的关系。C, 细根PC1和整株植物PC1之间的关系。

Fig. 2 Regression relationships among leaf PC1, fine root PC1 and whole-plant PC1. A, Regression relationships of leaf PC1 and fine root PC1. B, Regression relationships of leaf PC1 and whole-plant PC1. C, Regression relationships of fine root PC1 and whole-plant PC1. 
$L N C$ 与 $R P C$ 呈极显著正相关关系; $L P C$ 与 $R N C$ 也呈 显著正相关关系, 这表明武夷山木本植物叶片与细 根之间的化学元素存在协同共变。本研究中 $L N C$ 与 $R T D$ 的负相关关系表明, 该地区植物群落中, 一方 面存在着通过增加 $L N C$ 以提高其光合能力的快速生 长的物种 (即高 $L N C$ ), 另一方面, 还存在具有高根 组织支出的物种(即高 $R T D$ )。对于具有低 $L N C$ 的物种 来说, 建造具有高组织密度的根(即高 $R T D$ ) 用以提 高承受物理伤害的能力是一种昂贵的组织投资。因 此, 在整株植物水平上看, 具有高根组织密度的物 种对应于保守型的叶片策略(Westoby et al., 2002)和 缓慢生长(Reich, 2014); 反之, 低 $R T D$ 的物种因为具 有高 $L N C$, 倾向于快速生长。有研究指出, 当植物在 任何器官(叶和根)水平上是快速获取或使用碳(营养 元素或水)时, 将要求其在同一器官水平对其他资 源也是快速获取; 若某一器官水平(如叶水平)上的 所有资源均是快速获取, 则将要求其他器官水平 (如根水平)对所有资源也是快速获取(Reich, 2014)。 本研究中, 叶片、细根以及整株植物各性状贡献率 相对较大的PC1轴之间均是显著正相关的 $(p<0.05)$, 且常绿和落叶物种在性状轴上具有相同的分异现象, 表明叶片、细根以及整株植物之间的资源策略存在 协同变化, 说明亚热带木本植物叶片与细根遵循着 WPES策略的协调整合, 研究结果为全球尺度经济 谱研究提供了局地性的证据。

\section{2 常绿和落叶物种的经济谱特征}

本研究结果同样支持最初的假设2, 落叶物种 大部分分布在LES和WPES代表获取的一侧, 具有 较大的SLA、SRL和较高的养分含量, 而常绿物种分 布在保守一侧, 具有较大的 $R T D$ 和较高的碳含量。 表明即便处于相同的环境, 不同物种也具有不同的 响应策略(肖迪等, 2016)。根据PCA分析(图1)以及对 不同器官PC1轴得分进行独立样本 $t$ 检验的结果(表5) 可以发现, 本研究中常绿和落叶物种在植物经济谱 中的分布存在显著差异。除此之外, 叶片与细根间 PC1得分及其与整株植物PC1得分之间的关系也支 持假设2。本研究中, 落叶物种在叶片PC1与细根 PC1关系上无显著相关性, 且常绿和落叶物种在叶 片PC1、细根PC1和整株植物PC1轴之间关系上的斜 率不存在显著差异(即存在共同斜率), 但二者在截 距上存在显著差异, 体现了常绿物种的叶片和细根 间的关系比落叶物种更为密切, 且常绿和落叶物种
通过回归关系中截距上的差异来响应叶习性的变 化。一方面, 不变的斜率表明, 常绿和落叶物种在器 官和整株植物水平上具有恒定或一致的保守或获取 策略(Freschet et al., 2010; Reich, 2014; Díaz et al., 2016); 另一方面, 截距的差异表明常绿和落叶物种 构建WPES的方式存在差异。植物通过长期进化形 成了常绿与落叶这两种不同的生活史对策(李俊慧 等, 2017)。常绿和落叶物种的差异表现在物候 (Monk, 1966; Lusk et al., 2008), 叶片寿命(Westoby et al., 2002; van Ommen Kloeke et al., 2012), 养分利 用效率(Aerts, 1999; Warren \& Adams, 2004)等方面。 叶片常绿的主要优势在于光合作用季节较长、叶片 结构缓冲成本和更换叶片营养缓冲成本较低等; 而 落叶的优势在于单位叶片光合速率较高、在不利季 节根系成本较低且无叶片呼吸消耗(Givnish, 2002)。 有研究表明, 常绿是对低资源可用性的适应性反应, 落叶物种是对减少干旱期间水分损失的适应(Monk, 1966; Givnish, 2002; Warren \& Adams, 2004; Lusk et al., 2008; Méndez-Alonzo et al., 2012; Zhao et al., 2017)。常绿物种的叶片通常更厚, 需要将更多的生 物量分配于机械支撑, 这部分是为在不利的季节抵 御霜冻或干旱以免遭到不可挽回的损害(Chabot \& Hicks, 1982), 倾向于采取保守策略。而养分再吸收 效率较低的落叶物种叶寿命短(白坤栋等, 2015; 刘 璐等, 2019), 为满足较高养分含量的需求, 倾向于 采取获取策略。在武夷山亚热带环境中, 沿着LES 和WPES能够区分出常绿和落叶的物种, 但常绿和 落叶物种在RES上没有相互分离(表5; 图1B)。有一 种可能是由于实验限制导致没有进行早期和晚期落 叶物种的区分(Zhao et al., 2017), 另一种可能是由 于常绿和落叶物种内部性状存在较大的差异, 大部 分根性状都有较大的变异系数, 不同的物种有各自 的生存策略。因此, 尽管不同条件(如资源和干扰方 式)下不同性状的选择具有重要意义(Díaz et al., 1998), 但不同系统中快速(落叶)或慢速(常绿)物种 在性状、器官和资源之间的协调仍然趋于一致 (Reich, 2014)。

\section{4 结论}

通过对49种亚热带木本植物主要叶片性状与细 根性状的分析, 本研究验证了整株植物各器官性状 的耦合以及植物经济谱的存在, 确定了常绿和落叶 
物种在经济谱“投资-收益”策略轴中沿两个不同方 向的分异特征。这为全球植物经济谱背景下探讨综 合的WPES提供了有力的局地性证据, 进一步丰富 了具有不同叶习性的物种与植物经济谱的整合研究, 对理解生态位分化和物种共存机制等具有重要理论 和现实意义。

\section{参考文献}

Aerts R (1995). The advantages of being evergreen. Trends in Ecology \& Evolution, 10, 402-407.

Aerts R (1999). Interspecific competition in natural plant communities: mechanisms, trade-offs and plant-soil feedbacks. Journal of Experimental Botany, 50, 29-37.

Bai KD, Mo L, Liu M, Zhang DN, He CX, Wan XC, Jiang DB (2015). Nutrient resorption patterns of evergreen and deciduous tree species at different altitudes on Mao'er Mountain, Guangxi. Acta Ecologica Sinica, 35, 5776-5787. [白坤栋, 莫凌, 刘铭, 张德楠, 何成新, 万 贤崇, 蒋得斌 (2015). 广西猫儿山不同海拔常绿和落叶 树种的营养再吸收模式. 生态学报, 35, 5776-5787.]

Baraloto C, Timothy Paine CE, Poorter L, Beauchene J, Bonal D, Domenach AM, Hérault B, Patiño S, Roggy JC, Chave $\mathrm{J}$ (2010). Decoupled leaf and stem economics in rain forest trees. Ecology Letters, 13, 1338-1347.

Chabot BF, Hicks DJ (1982). The ecology of leaf life spans. Annual Review of Ecology and Systematics, 13, 229-259.

Chapin III FS (1980). The mineral nutrition of wild plants. Annual Review of Ecology and Systematics, 11, 233-260.

Chen GS, Hobbie SE, Reich PB, Yang YS, Robinson D (2019). Allometry of fine roots in forest ecosystems. Ecology Letters, 22, 322-331.

Chen YT, Xu ZZ (2014). Review on research of leaf economics spectrum. Chinese Journal of Plant Ecology, 38, 1135-1153. [陈芗婷, 许振柱 (2014). 植物叶经济谱的研究进展. 植物生态学报, 38, 1135-1153.]

Cornelissen JHC, Lavorel S, Garnier E, Díaz S, Buchmann N, Gurvich DE, Reich PB, ter Steege H, Morgan HD, van der Heijden MGA, Pausas JG, Poorter H (2003). A handbook of protocols for standardised and easy measurement of plant functional traits worldwide. Australian Journal of Botany, 51, 335-380.

Craine JM, Lee WG (2003). Covariation in leaf and root traits for native and non-native grasses along an altitudinal gradient in New Zealand. Oecologia, 134, 471-478.

Craine JM, Lee WG, Bond WJ, Williams RJ, Johnson LC (2005). Environmental constraints on a global relationship among leaf and root traits of grasses. Ecology, 86, 12-19.

de la Riva EG, Tosto A, Pérez-Ramos IM, Navarro-Fernández CM, Olmo M, Anten NPR, Marañón T, Villar R (2016). A plant economics spectrum in Mediterranean forests along environmental gradients: is there coordination among leaf, stem and root traits? Journal of Vegetation Science, 27, 187-199.

Díaz S, Cabido M, Casanoves F (1998). Plant functional traits and environmental filters at a regional scale. Journal of Vegetation Science, 9, 113-122.

Díaz S, Kattge J, Cornelissen JHC, Wright IJ, Lavorel S, Dray S, Reu B, Kleyer M, Wirth C, Colin Prentice I, Garnier E, Bönisch G, Westoby M, Poorter H, Reich PB, et al. (2016). The global spectrum of plant form and function. Nature, 529, 167-171.

Ding JX, Kong DL, Zhang ZL, Cai Q, Xiao J, Liu Q, Yin HJ (2020). Climate and soil nutrients differentially drive multidimensional fine root traits in ectomycorrhizal-dominated alpine coniferous forests. Journal of Ecology, 108, 2544-2556.

Eissenstat DM, Yanai RD (1997). The ecology of root lifespan. Advances in Ecological Research, 27, 1-60.

Fortunel C, Fine PVA, Baraloto C (2012). Leaf, stem and root tissue strategies across 758 Neotropical tree species. Functional Ecology, 26, 1153-1161.

Freschet GT, Cornelissen JHC, van Logtestijn RSP, Aerts R (2010). Evidence of the "plant economics spectrum" in a subarctic flora. Journal of Ecology, 98, 362-373.

Freschet GT, Cornwell WK, Wardle DA, Elumeeva TG, Liu WD, Jackson BG, Onipchenko VG, Soudzilovskaia NA, Tao JP, Cornelissen JHC (2013). Linking litter decomposition of above- and below-ground organs to plant-soil feedbacks worldwide. Journal of Ecology, 101, 943-952.

Funk JL, Cornwell WK (2013). Leaf traits within communities: context may affect the mapping of traits to function. Ecology, 94, 1893-1897.

Geng Y, Wang L, Jin DM, Liu HY, He JS (2014). Alpine climate alters the relationships between leaf and root morphological traits but not chemical traits. Oecologia, 175, 445-455.

Givnish TJ (2002). Adaptive significance of evergreen vs. deciduous leaves: solving the triple paradox. Silva Fennica, 36, 703-743.

Grime JP, Thompson K, Hunt R, Hodgson JG, Cornelissen JHC, Rorison IH, Hendry GAF, Ashenden TW, Askew AP, Band SR, Booth RE, Bossard CC, Campbell BD, Cooper JEL, Davison AW, et al. (1997). Integrated screening validates primary axes of specialisation in plants. Oikos, 79, 259-281.

He YY, Guo SL, Wang Z (2019). Research progress of trade-off relationships of plant functional traits. Chinese Journal of Plant Ecology, 43, 1021-1035. [何芸雨, 郭水 良, 王喆 (2019). 植物功能性状权衡关系的研究进展. 植物生态学报, 43, 1021-1035.]

Isaac ME, Martin AR, de Melo Virginio Filho E, Rapidel B, Roupsard O, van den Meersche K (2017). Intraspecific

www.plant-ecology.com 
trait variation and coordination: root and leaf economics spectra in coffee across environmental gradients. Frontiers in Plant Science, 8, 1196. DOI: 10.3389/fpls.2017.01196.

Kong DL, Wang JJ, Kardol P, Wu HF, Zeng H, Deng XB, Deng Y (2016). Economic strategies of plant absorptive roots vary with root diameter. Biogeosciences, 13, 415-424.

Kong DL, Wang JJ, Wu HF, Valverde-Barrantes OJ, Wang RL, Zeng H, Kardol P, Zhang HY, Feng YL (2019). Nonlinearity of root trait relationships and the root economics spectrum. Nature Communications, 10, 2203. DOI: 10. 1038/s41467-019-10245-6.

Li FL, Hu H, McCormlack ML, Feng DF, Liu X, Bao WK (2019). Community-level economics spectrum of fine-roots driven by nutrient limitations in subalpine forests. Journal of Ecology, 107, 1238-1249.

Li JH, Peng GQ, Yang DM (2017). Effect of stem length to stem slender ratio of current-year twigs on the leaf display efficiency in evergreen and deciduous broadleaved trees. Chinese Journal of Plant Ecology, 41, 650-660. [李俊慧, 彭国全, 杨冬梅 (2017). 常绿和落叶阔叶物种当年生小 枝茎长度和茎纤细率对展叶效率的影响. 植物生态学 报, 41, 650-660.]

Liu GF, Freschet GT, Pan X, Cornelissen JHC, Li Y, Dong M (2010). Coordinated variation in leaf and root traits across multiple spatial scales in Chinese semi-arid and arid ecosystems. New Phytologist, 188, 543-553.

Liu L, Ge JL, Shu HW, Zhao CM, Xu WT, Shen GZ, Xie ZQ (2019). C, N and P stoichiometric ratios in mixed evergreen and deciduous broadleaved forests in Shennongjia, China. Chinese Journal of Plant Ecology, 43, 482-489. [刘 璐, 葛结林, 舒化伟, 赵常明, 徐文婷, 申国珍, 谢宗强 (2019). 神农架常绿落叶阔叶混交林碳氮磷化学计量比. 植物生态学报, 43, 482-489.]

Liu XZ, Fang FS (2001). Scientific Survey of the Wuyishan Nature Reserve in Jiangxi. China Forestry Publishing House, Beijing. [刘信中, 方福生 (2001). 江西武夷山自 然保护区科学考察集. 中国林业出版社, 北京.]

Lusk CH, Reich PB, Montgomery RA, Ackerly DD, CavenderBares J (2008). Why are evergreen leaves so contrary about shade? Trends in Ecology \& Evolution, 23, 299-303.

Ma ZQ, Guo DL, Xu XL, Lu MZ, Bardgett RD, Eissenstat DM, McCormack ML, Hedin LO (2018). Evolutionary history resolves global organization of root functional traits. $\mathrm{Na}$ ture, 555, 94-97.

Mao W, Li YL, Zhang TH, Zhao XY, Huang YX, Song LL (2012). Research advances of plant leaf traits at different ecology scales. Journal of Desert Research, 32, 33-41. [毛 伟, 李玉霖, 张铜会, 赵学勇, 黄迎新, 宋琳琳 (2012). 不同尺度生态学中植物叶性状研究概述. 中国沙漠, 32, 33-41.]

Medeiros JS, Burns JH, Nicholson J, Rogers L, ValverdeBarrantes O (2017). Decoupled leaf and root carbon eco- nomics is a key component in the ecological diversity and evolutionary divergence of deciduous and evergreen lineages of genus Rhododendron. American Journal of Botany, 104, 803-816.

Méndez-Alonzo R, Paz H, Zuluaga RC, Rosell JA, Olson ME (2012). Coordinated evolution of leaf and stem economics in tropical dry forest trees. Ecology, 93, 2397-2406.

Monk CD (1966). An ecological significance of evergreenness. Ecology, 47, 504-505.

Pérez-Ramos IM, Roumet C, Cruz P, Blanchard A, Autran P, Garnier E (2012). Evidence for a "plant community economics spectrum" driven by nutrient and water limitations in a Mediterranean rangeland of southern France. Journal of Ecology, 100, 1315-1327.

Poorter H, Lambers H, Evans JR (2014). Trait correlation networks: a whole-plant perspective on the recently criticized leaf economic spectrum. New Phytologist, 201, 378-382.

Prieto I, Roumet C, Cardinael R, Dupraz C, Jourdan C, Kim JH, Maeght JL, Mao Z, Pierret A, Portillo N, Roupsard O, Thammahacksa C, Stokes A (2015). Root functional parameters along a land-use gradient: evidence of a communitylevel economics spectrum. Journal of Ecology, 103, 361-373.

Qu P, Xing YJ, Wang QG (2018). Research progress of plant economic spectrum. Chinese Agricultural Science Bulletin, 34, 88-94. [曲鹏, 邢亚娟, 王庆贵 (2018). 植物经济谱 研究进展. 中国农学通报, 34, 88-94.]

Reich PB (2014). The world-wide "fast-slow" plant economics spectrum: a traits manifesto. Journal of Ecology, 102, 275-301.

Reich PB, Ellsworth DS, Walters MB, Vose JM, Gresham C, Volin JC, Bowman WD (1999). Generality of leaf trait relationships: a test across six biomes. Ecology, 80, 1955-1969.

Reich PB, Tjoelker MG, Walters MB, Vanderklein DW, Buschena C (1998). Close association of RGR, leaf and root morphology, seed mass and shade tolerance in seedlings of nine boreal tree species grown in high and low light. Functional Ecology, 12, 327-338.

Reich PB, Walters MB, Ellsworth DS (1997). From tropics to tundra: global convergence in plant functioning. Proceedings of the National Academy of Sciences of the United States of America, 94, 13730-13734.

Reich PB, Wright IJ, Cavender-Bares J, Craine JM, Oleksyn J, Westoby M, Walters MB (2003). The evolution of plant functional variation: traits, spectra, and strategies. International Journal of Plant Sciences, 164, S143-S164.

Roumet C, Birouste M, Picon-Cochard C, Ghestem M, Osman N, Vrignon-Brenas S, Cao KF, Stokes A (2016). Root structure-function relationships in 74 species: evidence of a root economics spectrum related to carbon economy. New Phytologist, 210, 815-826.

Tang QQ, Huang YT, Ding Y, Zang RG (2016). Interspecific 
and intraspecific variation in functional traits of subtropical evergreen and deciduous broad-leaved mixed forests. Biodiversity Science, 24, 262-270. [唐青青, 黄永涛, 丁 易, 藏润国 (2016). 亚热带常绿落叶阔叶混交林植物功 能性状的种间和种内变异. 生物多样性, 24, 262-270.]

Tjoelker MG, Craine JM, Wedin D, Reich PB, Tilman D (2005). Linking leaf and root trait syndromes among 39 grassland and savannah species. New Phytologist, 167, 493-508.

van Ommen Kloeke AEE, Douma JC, Ordoñez JC, Reich PB, van Bodegom PM (2012). Global quantification of contrasting leaf life span strategies for deciduous and evergreen species in response to environmental conditions. Global Ecology and Biogeography, 21, 224-235.

Venables WN, Smith DM, The R Core Team (2019). An introduction to R. Notes on R: a programming environment for data analysis and graphics. Version 3.6.0 RC (2019-0424). [2019-04-27]. http://ydl.oregonstate.edu/pub/cran/doc /manuals/r-patched/R-intro.pdf.

Wang M, Wan PC, Guo JC, Xu JS, Chai YF, Yue M (2017). Relationships among leaf, stem and root traits of the dominant shrubs from four vegetation zones in Shaanxi Province, China. Israel Journal of Ecology and Evolution, 63, 25-32.

Warren CR, Adams MA (2004). Evergreen trees do not maximize instantaneous photosynthesis. Trends in Plant Science, 9, 270-274.

Warton DI, Weber NC (2002). Common slope tests for bivariate errors-in-variables models. Biometrical Journal, 44, 161-174.

Warton DI, Wright IJ, Falster DS, Westoby M (2006). Bivariate line-fitting methods for allometry. Biological Reviews, 81, 259-291.

Westoby M, Falster DS, Moles AT, Vesk PA, Wright IJ (2002). Plant ecological strategies: some leading dimensions of variation between species. Annual Review of Ecology and Systematics, 33, 125-159.

Withington JM, Reich PB, Oleksyn J, Eissenstat DM (2006). Comparisons of structure and life span in roots and leaves among temperate trees. Ecological Monographs, 76, 381-397.

Wright IJ, Reich PB, Cornelissen JHC, Falster DS, Groom PK, Hikosaka K, Lee W, Lusk CH, Niinemets Ü, Oleksyn J, Osada N, Poorter H, Warton DI, Westoby M (2005). Modulation of leaf economic traits and trait relationships by climate. Global Ecology and Biogeography, 14, 411-421.

Wright IJ, Reich PB, Westoby M, Ackerly DD, Baruch Z, Bongers F, Cavender-Bares J, Chapin T, Cornelissen JHC, Diemer M, Flexas J, Garnier E, Groom PK, Gulias J, Hikosaka K, et al. (2004). The worldwide leaf economics spectrum. Nature, 428, 821-827.

Xiao D, Wang XJ, Zhang K, He NP, Hou JH (2016). Effects of nitrogen addition on leaf traits of common species in natural Pinus tabuliformis forests in Taiyue Mountain, Shanxi Province, China. Chinese Journal of Plant Ecology, 40, 686-701. [肖迪, 王晓洁, 张凯, 何念鹏, 侯继华 (2016). 氮添加对山西太岳山天然油松林主要植物叶片性状的 影响. 植物生态学报, 40, 686-701.]

Yu HY, Chen YT, Xu ZZ, Zhou GS (2014). Analysis of relationships among leaf functional traits and economics spectrum of plant species in the desert steppe of Nei Mongol. Chinese Journal of Plant Ecology, 38, 1029-1040. [于鸿 荣, 陈荣婷, 许振柱, 周广胜 (2014). 内蒙古荒漠草原 植物叶片功能性状关系及其经济谱分析. 植物生态学 报, 38, 1029-1040.]

Zhao YT, Ali A, Yan ER (2017). The plant economics spectrum is structured by leaf habits and growth forms across subtropical species. Tree Physiology, 37, 173-185.

Zheng CY, Liu ZL, Fang JY (2004). Tree species diversity along altitudinal gradient on southeastern and northwestern slopes of Mt. Huanggang, Wuyi Mountains, Fujian, China. Biodiversity Science, 12, 63-74. [郑成洋, 刘增力, 方精云 (2004). 福建黄岗山东南坡和西北坡乔木物种 多样性及群落特征的垂直变化. 生物多样性, 12, 63-74.]

责任编委: 邓建明 责任编辑: 李 敏

附录 I 武夷山不同群落的物种类群概况

Supplement I Summary of species taxa of different communities in Wuyi Mountains https://www.plant-ecology.com/fileup/1005-264X/PDF/cjpe.2020.0280-S1.pdf 
王钊颖, 陈晓萍, 程英, 王满堂, 钟全林, 李曼, 程栋梁 (2021). 武夷山49种木本植物叶片与细根经济谱. 植 物生态学报, 45, 242-252. DOI: 10.17521/cjpe.2020.0280

Wang ZY, Chen XP, Cheng Y, Wang MT, Zhong QL, Li M, Cheng DL (2021). Leaf and fine root economics spectrum across 49 woody plant species in Wuyi Mountains. Chinese Journal of Plant Ecology, 45, 242-252. DOI: 10.17521/cjpe.2020.0280

https://www.plant-ecology.com/CN/10.17521/cjpe.2020.0280

附录 I 武夷山不同群落的物种类群概况

Supplement I Summary of species taxa of different communities in Wuyi Mountains

\begin{tabular}{|c|c|c|}
\hline 群落 & 物种 & 叶习性 \\
\hline Community & Species & Leaf habit \\
\hline \multirow[t]{21}{*}{ 常绿阔叶林 Evergreen forest } & 灯台树 Bothrocaryum controversum & 落叶 Deciduous \\
\hline & 东方古柯 Erythroxylum sinensis & 落叶 Deciduous \\
\hline & 东南石栎 Lithocarpus harlandii & 常绿 Evergreen \\
\hline & 多脉青冈 Cyclobalanopsis multinervis & 常绿 Evergreen \\
\hline & 栲树 Castanopsis fargesii & 常绿 Evergreen \\
\hline & 雷公鹅耳枥 Carpinus viminea & 落叶 Deciduous \\
\hline & 鹿角杜鹃 Rhododendron latoucheae & 常绿 Evergreen \\
\hline & 马银花 Rhododendron ovatum & 常绿 Evergreen \\
\hline & 大屿八角 Illicium angustisepalum & 常绿 Evergreen \\
\hline & 木荷 Schima superba & 常绿 Evergreen \\
\hline & 山槐 Albizia kalkora & 落叶 Deciduous \\
\hline & 水青冈 Fagus longipetiolata & 落叶 Deciduous \\
\hline & 坛果山矾 Symplocos urceolaris & 常绿 Evergreen \\
\hline & 甜槠 Castanopsis eyrei & 常绿 Evergreen \\
\hline & 尾叶冬青 Ilex wilsonii & 常绿 Evergreen \\
\hline & 细叶冬青 Ilex triflora & 常绿 Evergreen \\
\hline & 小叶白辛树 Pterostyrax corymbosus & 落叶 Deciduous \\
\hline & 小叶栲 Castanopsis carlesii & 常绿 Evergreen \\
\hline & 钥形叶鼠刺 Itea oblonga & 常绿 Evergreen \\
\hline & 樱桃 Cerasus pseudocerasus & 落叶 Deciduous \\
\hline & 锥栗 Castanea henryi & 落叶 Deciduous \\
\hline 针阔混交林 Coniferous and & 茶荚蒾 Viburnum setigerum & 落叶 Deciduous \\
\hline \multirow[t]{12}{*}{ broad-leaved mixed forest } & 短柱柃 Eurya brevistyla & 常绿 Evergreen \\
\hline & 多脉青冈 Cyclobalanopsis multinervis & 常绿 Evergreen \\
\hline & 红豆杉 Taxus chinensis & 常绿 Evergreen \\
\hline & 猴头杜鹃 Rhododendron simiarum & 常绿 Evergreen \\
\hline & 鸡爪槭 Acer palmatum & 落叶 Deciduous \\
\hline & 截叶连荵茶 Camellia truncata & 常绿 Evergreen \\
\hline & 鹿角杜鹃 Rhododendron latoucheae & 常绿 Evergreen \\
\hline & 大屿八角 Illicium angustisepalum & 常绿 Evergreen \\
\hline & 木姜子 Litsea pungens & 落叶 Deciduous \\
\hline & 南方铁杉 Tsuga chinensis & 常绿 Evergreen \\
\hline & 石栋 Lithocarpus glaber & 常绿 Evergreen \\
\hline & 坛果山矾 Symplocos urceolaris & 常绿 Evergreen \\
\hline
\end{tabular}


附录 I (续) Supplement I (Continued)

\begin{tabular}{|c|c|c|}
\hline 群落 & 物种 & 叶习性 \\
\hline Community & Species & Leaf habit \\
\hline \multirow{26}{*}{ 落叶林 Deciduous forest } & 香港四照花 Dendrobenthamia hongkongensis & 常绿 Evergreen \\
\hline & 秀丽槭 Acer elegantulum & 落叶 Deciduous \\
\hline & 岩柃 Eurya saxicola & 常绿 Evergreen \\
\hline & 银钟花 Halesia macgregorii & 落叶 Deciduous \\
\hline & 云锦杜鹃 Rhododendron fortunei & 常绿 Evergreen \\
\hline & 白蜡树 Fraxinus chinensis & 落叶 Deciduous \\
\hline & 白檀 Symplocos paniculata & 落叶 Deciduous \\
\hline & 稠李 Padus racemosa & 落叶 Deciduous \\
\hline & 灯笼花 Fuchsia hybrida & 落叶 Deciduous \\
\hline & 短柱柃 Eurya brevistyla & 常绿 Evergreen \\
\hline & 多脉青冈 Cyclobalanopsis multinervis & 常绿 Evergreen \\
\hline & 合轴荚蒾 Viburnum sympodiale & 落叶 Deciduous \\
\hline & 华东山柳 Clethra barbinervis & 落叶 Deciduous \\
\hline & 鸡爪槭 Acer palmatum & 落叶 Deciduous \\
\hline & 毛果槭 Acer nikoense & 落叶 Deciduous \\
\hline & 梅叶冬青 Ilex asprella & 落叶 Deciduous \\
\hline & 大屿八角 Illicium angustisepalum & 常绿 Evergreen \\
\hline & 泡花树 Meliosma cuneifolia & 落叶 Deciduous \\
\hline & 三桠乌药 Lindera obtusiloba & 落叶 Deciduous \\
\hline & 坛果山矾 Symplocos urceolaris & 常绿 Evergreen \\
\hline & 天目木兰 Magnolia amoena & 落叶 Deciduous \\
\hline & 天目紫茎 Stewartia gemmata & 落叶 Deciduous \\
\hline & 岩柃 Eurya saxicola & 常绿 Evergreen \\
\hline & 野花椒 Zanthoxylum simulans & 落叶 Deciduous \\
\hline & 云锦杜鹃 Rhododendron fortunei & 常绿 Evergreen \\
\hline & 中华石楠 Photinia beauverdiana & 落叶 Deciduous \\
\hline
\end{tabular}

